\title{
Retailer-Supplier Matching: an Application of the Deferred Acceptance Algorithm
}

\author{
Taewoo Jung Changhyun Kwon
}

June 9,2011

\begin{abstract}
In this paper, we apply matching theory to supply chain coordination. We present mathematical optimization models similar to the newsvendor problem to provide appropriate conditions for retailer-supplier matching. In particular, our matching algorithm, compared to the general matching theory, has uniquely been affected by contract sizes and ordering sequences. We also study that our matching application guarantees stable and optimal outcomes. Numerical examples with various parameter settings are provided to test the feasibility of the matching algorithms. We find that we can avoid the worst matching case when we use the proposed matching algorithms.
\end{abstract}

\section{Introduction}

Since Gale and Shapley (1962) introduced a matching algorithm for college admission problems, matching theory has been one of widely discussed topics in game theory, and education economics to efficiently place students on public schools. Recently big cities in the U.S. such as Boston, New York City and Seattlef have virtually been using the matching system to satisfy both schools and students in their preference orders. Traditional supply chain management has not considered preference-based systems between retailers and suppliers, although there are a lot of good characteristics of matching theory for allocation system.

In this paper, we develop a new framework that allows us to effectively match retailers and suppliers in a matching algorithm which we call retailer-supplier matching with the Deferred Acceptance Algorithm (Gale and Shapley, 1962) and subsequently to consider stability and optimality of the matching outcomes satisfying various scenarios that occur in retailersupplier contract situations. A central issue we address is how retailers and suppliers can order and offer their optimal quantities under full information about their matching partners. In particular, we determine each retailer's optimal ordering quantity and each supplier's optimal offering quantity from stochastic optimization models that are similar to the newsvendor model. 
There are many papers in economics literatures dealing with school-choice allocations by the matching theory, including Abdulkadiroglu and Sonmez (2003). Just as our retailersupplier matching model, the Deferred Acceptance Algorithm, one of the matching algorithms, has widely been used for emplaning not only school choice allocations, but also for nurses allocations problem in hospitals studied. In addition to various applications of the matching theory, its important properties including stability and optimality have been also studied by Roth $(1982,2008)$.

The relationship between retailers and suppliers has been studied in the perspective of supplier selection (De Boer et al., 2001) and outsourcing policies (Elmaghraby, 2000), rather than matching. An interesting selection method that has (limited) similarities with the proposed retailer-supplier matching is a supplier tournament (Deng and Elmaghraby, 2005), where a retailer procures from two suppliers in the initial time periods and later only one supplier is selected. In the retailer-supplier matching considered in this paper, however, selections among multiple suppliers (or retailers) occur, but actual procurements occur only after all selections (matching) are made.

The retailer-supplier matching in this paper requires a method to determine preferences of retailers and suppliers. We use stochastic optimization models similar to the well-known newsvendor model and the considered profit function in concave as similar as in Cachon (1999), Zhang (2008) and Sobel and Turcic (2008).

This paper will be organized as follows. Section 2 selectively reviews the most widely used matching theory, the Deferred Acceptance Algorithm proposed by Gale and Shapley (1962). Section 3 provides stochastic optimization models to determine preferences of retailers and suppliers, which will be basis for matching. Section 4 introduces retailer-supplier matching algorithms. We then discuss the stability and optimality of the matching results in Section 5. In Section 6, we suggest numerical illustrations including relevant steps for the algorithm, and also the results are compared to each other in different matching scenarios.

\section{Deferred Acceptance Algorithm}

In this section, we present a brief explanation of Deferred Acceptance Algorithm (DA algorithm) which is the most typical matching algorithm over several other matching algorithms. In addition, we illustrate the DA algorithm with a student-school matching case, where the matching is based on the preferences of students and schools. Students have their own preference for the schools, reflecting the preferences to their applications. Likewise, the schools also have their own preference over the students, accepting students under their preferences. The process of the algorithm is run through the following steps.

In the first step, each student applies for his first choice school. Each school tentatively accepts an applicant who has the highest preference for the school, and the rest are rejected. 
At the $k$-th step, each student who was rejected in $(k-1)$-st step applies to his next choice school. For each school, the highest preference applicant among the new applicant and those who were tentatively placed at a previous step are tentatively placed to the school, and the rest are rejected. The algorithm terminates when no student is rejected any more.

Let us consider an example of student-school matching. We consider a group of students $\left\{s_{1}, s_{2}, s_{3}, s_{4}\right\}$ and a group of schools $\left\{c_{1}, c_{2}, c_{3}, c_{4}\right\}$ where each school has only one seat (capacity) to admit one student. The preferences of schools and students are given in Table 1.

\begin{tabular}{c|cccc||cccc}
\hline \hline rank & $s_{1}$ & $s_{2}$ & $s_{3}$ & $s_{4}$ & $c_{1}$ & $c_{2}$ & $c_{3}$ & $c_{4}$ \\
\hline 1 & $c_{2}$ & $c_{2}$ & $c_{2}$ & $c_{3}$ & $s_{1}$ & $s_{1}$ & $s_{1}$ & $s_{3}$ \\
2 & $c_{3}$ & $c_{1}$ & $c_{1}$ & $c_{1}$ & $s_{2}$ & $s_{3}$ & $s_{4}$ & $s_{2}$ \\
3 & $c_{1}$ & $c_{3}$ & $c_{4}$ & $c_{2}$ & $s_{4}$ & $s_{2}$ & $s_{3}$ & $s_{1}$ \\
4 & $c_{4}$ & $c_{4}$ & $c_{3}$ & $c_{4}$ & $s_{3}$ & $s_{4}$ & $s_{2}$ & $s_{4}$ \\
\hline \hline
\end{tabular}

Table 1: Preferences of Students and Schools

From Table 1, we confirm the preference order for each school and student. For example, Student $1\left(s_{1}\right)$ has a preference order such that School $2\left(c_{2}\right)$ on the first rank, School $3\left(c_{3}\right)$ on the second rank, School $1\left(c_{1}\right)$ on the third rank, School $4\left(c_{4}\right)$ on the last rank. School 1 $\left(c_{1}\right)$ has a preference order such that Student $1\left(s_{1}\right)$ on the first rank, Student $2\left(s_{2}\right)$ on the second rank, Student $4\left(s_{4}\right)$ on the third rank, and Student $3\left(s_{3}\right)$ on the last rank.

\begin{tabular}{c|cccc}
\hline \hline Round & $c_{1}$ & $c_{2}$ & $c_{3}$ & $c_{4}$ \\
\hline 1 & - & $\mathbf{s}_{1}, s_{2}, s_{3}$ & $\mathbf{s}_{\mathbf{4}}$ & - \\
2 & $\mathbf{s}_{2}, s_{3}$ & $\mathbf{s}_{\mathbf{1}}$ & $\mathbf{s}_{\mathbf{4}}$ & - \\
3 & $\mathbf{s}_{\mathbf{2}}$ & $\mathbf{s}_{\mathbf{1}}$ & $\mathbf{s}_{\mathbf{4}}$ & $\mathbf{s}_{\mathbf{3}}$ \\
\hline \hline
\end{tabular}

Table 2: DA Matching Algorithm

The DA algorithm applied to this problem is given in Table 2. The outcome of DA algorithm for this problem has been finalized in Round 3. In Round 1, Student 1, Student 2, Student 3 apply for School 2 as their first preference is School 2. On the other hand, Student 4 applies to School 3. School 2 tentatively accepts Student 1 as marked bold in the table, rejecting other applicants. Similarly in Round 2, Student 2 and Student 3 who were rejected in Round 1 apply for School 1 as their second preference is same as School 1. Then School 1 only accepts Student 2 rejecting Student 3. Finally in Round 3, Student 3 applies for School 4, completing all matching pairs. Hence, this algorithm provides student-school pairs: $\left(s_{1}, c_{2}\right),\left(s_{2}, c_{1}\right),\left(s_{3}, c_{4}\right)$ and $\left(s_{4}, c_{3}\right)$. 


\begin{tabular}{cl}
\hline \hline Symbol & Definition \\
\hline$p$ & unit price for the product by retailers $i$ \\
$U_{i}$ & profit of retailer $i$ \\
$V_{j}$ & profit function for supplier $j$ \\
$O_{i}$ & order quantity of retailer $i$ \\
$S_{i j}$ & offering quantity of supplier $j$ for retailer $i$ \\
$D_{i}$ & random demand for retailer $i$ \\
$h_{i}$ & shortage cost for retailer $i$ \\
$r_{i j}$ & buy-back costs of supplier $j$ from retailer $i$ \\
$c$ & unit purchase cost of retailers from suppliers \\
$m_{j}$ & unit production cost of supplier $j$ \\
$F_{i}(x)$ & c.d.f demand function for retailer $i$ \\
\hline \hline
\end{tabular}

Table 3: Notation

\section{Preferences of Retailers and Suppliers}

In this section, we provide models for determining the preference orders of retailers and suppliers. Both retailers and suppliers determine their preferred order of opponents based on own profit maximization. We formulate stochastic optimization models which are similar to the well-known newsvendor problem. We use the notation presented in Table 3 throughout the paper.

\subsection{Retailer's Model}

We consider a single period newsvendor problem in which the retailers choose their optimal quantities for profit maximization. In this model, we consider buy-back of any left-over after sales season. That is, retailers can create revenue by selling any inventory more than realized demands to the original suppliers. We assume that the selling prices for all retailers are same. The retailers have two modes of the ordering: (1) the order quantity is less than the realized demand, and (2) the order quantity is greater than the realized demand. In Mode (1), shortage costs are incurred with $h_{i}>p$. In Mode (2), retailers gain salvage values for the left-over with $r_{i j}<c$.

Given the order quantity $O_{i j}$, the utility of each retailer $i$ is determined by the following function:

$$
\begin{aligned}
& U_{i j}\left(O_{i j}\right)=p \mathbb{E}\left[\min \left(O_{i j}, D_{i}\right)\right]-h_{i} \mathbb{E}\left[\max \left(D_{i}-O_{i j}, 0\right)\right] \\
&+r_{i j} \mathbb{E}\left[\max \left(O_{i j}-D_{i}, 0\right)\right]-c O_{i j}
\end{aligned}
$$

when retailer $i$ purchases from supplier $j$. Each term represents the expected profit, the expected shortage cost, the expected salvage value and the purchase cost, respectively. The 
utility (1) is same as in the newsvendor problem. Let us define

$$
O_{i j}^{*}=\arg \max U_{i j}\left(O_{i j}\right)
$$

We can easily show the strict concavity of $U_{i j}$, and hence the uniqueness of $O_{i j}^{*}$. The following result is obtained.

Proposition 1. The profit function for any retailer $i, U_{i j}\left(O_{i j}\right)$, is a strictly concave function for all suppliers $j$, and it is maximized at

$$
O_{i j}^{*}=F_{i}^{-1}\left(\frac{h_{i}+p-c}{h_{i}+p-r_{i j}}\right)
$$

\subsection{Supplier's Model}

The suppliers offer their product quantities based on their profit maximization functions which consist of identical offering price, buy-back costs from matched retailers and production costs. The unit sales price of the product from suppliers is assumed to be same for all suppliers and retailers. The buy-back quantity must be dependent on the nature of random demand of each retailer, therefore the unit buy-back cost is also assumed to be different for each retailer and each supplier.

Given the shipping quantity $S_{i j}$, the utility of each supplier $j$ is determined by the following profit function:

$$
\left.V_{i j}\left(S_{i j}\right)=c S_{i j}-r_{i j} \mathbb{E}\left[\max \left(S_{i j}-D_{i}\right), 0\right)\right]-m_{j} S_{i j}
$$

when supplier $j$ ships to retailer $i$. Each term in (4) represents the revenue, the expected buy-back cost, and the production cost, respectively. We define

$$
S_{i j}^{*}=\arg \max V_{i j}\left(S_{i j}\right)
$$

Proposition 2. The profit function for any supplier $j, V_{i j}\left(S_{i j}\right)$, is a strictly concave function for all retailers $i$, and it is maximized at

$$
S_{i j}^{*}=F_{i}^{-1}\left(\frac{c-m_{j}}{r_{i j}}\right)
$$

Proof. From the first-order condition, we obtain

$$
\left(c-m_{j}\right)-r_{i j} F_{i}\left(S_{i j}\right)=0
$$


Thus, we obtain (6). The second-order condition shows that $V_{i j}\left(S_{i j}\right)$ is strictly concave:

$$
\frac{\partial^{2} V_{i j}}{\partial S_{i j}^{2}}=-r_{i j} f_{i}\left(S_{i j}\right)<0
$$

since $r_{i j}$ is always positive.

\subsection{Preferences}

Let us consider retailer $i$. Suppose the order quantity of retailer $i$ is determined as $z_{i j}$ when retailer $i$ procures from supplier $j$. That is, retailer $i$ considers the following set of order quantities:

$$
\left\{z_{i 1}, z_{i 2}, \ldots, z_{i n}\right\}
$$

and the set of corresponding utilities:

$$
\left\{U_{i 1}\left(z_{i 1}\right), U_{i 2}\left(z_{i 2}\right), \ldots, U_{i n}\left(z_{i n}\right)\right\}
$$

Retailer $i$ prefers supplier $j$ to supplier $j^{\prime}$ when $U_{i j}\left(z_{i j}\right)>U_{i j^{\prime}}\left(z_{i j^{\prime}}\right)$. When the two utility function values are same, the preferred supplier is determined randomly. We define the ordered set of preferred suppliers of retailer $i$ as

$$
\Omega_{i}=\left\{i_{1}, i_{2}, \ldots, i_{n}\right\}
$$

where $U_{i i_{1}}\left(z_{i i_{1}}\right)>U_{i i_{2}}\left(z_{i i_{2}}\right)>\ldots>U_{i i_{n}}\left(z_{i i_{n}}\right)$.

Similarly, given the shipping quantities $z_{i j}$, we define the ordered set of preferred retailers of supplier $j$ as

$$
\Lambda_{j}=\left\{j_{1}, j_{2}, \ldots, j_{n}\right\}
$$

where $V_{j_{1} j}\left(z_{j_{1} j}\right)>V_{j_{2} j}\left(z_{j_{2} j}\right)>\ldots>V_{j_{n} j}\left(z_{j_{n} j}\right)$. We discuss how $z_{i j}$ may be determined in the following section.

\section{Retailer-Supplier Matching Algorithm}

In the retailer-supplier matching, the mechanism has two control factors:

1. How the actual contract size is determined; and

2. Who proposes matching first: retailers or suppliers.

The first factor impacts on the determination of ordered set of preferences, while the second factor impacts the outcome of matching is optimal to which party. 
For the first factor, we consider the following three cases of the actual contract size $z_{i j}$ of retailer $i$ and supplier $j$ :

1. $z_{i j}=O_{i j}^{*}$ : When retailer $i$ and supplier $j$ make a contract, the retailer $i$ 's optimal order quantity, $o_{i j}^{*}$ is used.

2. $z_{i j}=S_{i j}^{*}$ : When retailer $i$ and supplier $j$ make a contract, the supplier $j$ 's optimal production quantity, $s_{i j}^{*}$ is used.

When the contract size $z_{i j}$ is determined, the ordered sets of preference are determined as explained in Section 3.3.

We consider the retailer-first and the supplier-first mechanisms for the second control factor. When combined with a choice of $z_{i j}$, in total four possible matching algorithms can be obtained. The supplier-first matching algorithm with $z_{i j}=O_{i j}^{*}$ is given below. The other three algorithms can be stated similarly.

\section{Supplier-First Matching Algorithm with $z_{i j}=O_{i j}^{*}$}

Step 0. Each retailer is able to obtain optimal ordering quantities for all suppliers, so that each retailer $i$ has $o_{i 1}^{*}, o_{i 2}^{*}, o_{i 3}^{*} \ldots$. Using the optimal orders and the corresponding expected profits, the suppliers and retailers determined preference lists.

Step 1. The suppliers offer the first preferred quantity to the corresponding retailer.

Step 2. The retailers who received any offer accept the most preferred offer among the offers and reject all other offers.

Step 3. Rejected suppliers re-offer with their second choices from the preference list. The retailers who received new offers compare the already accepted offer, if any, with the new offers and accept the best offer among them.

Step 4. The algorithm is repeated until there is no unmatched retailer and supplier.

\section{$5 \quad$ Stability and Optimality of the Retailer-Supplier Matching}

This section studies the stability of the retailer-supplier matching proposed in the previous section. Suppose that Retailer 1 is currently matched with Supplier 1, and Retailer 2 is with Supplier 2. This matching is called unstable, if Retailer 1 prefers Supplier 2 to Supplier 1 and Supplier 1 prefers Retailer 1 to Retailer 2. In this case, Retailer 1 and Supplier 2 are both better off with doing business together; we call the pair of Retailer 1 and Supplier 2 a blocking pair. If there is no blocking pair in a matching, we call the matching stable. It is well known that the Deferred Acceptance Algorithm produces a stable matching. 


\begin{tabular}{|c||c|c|c|c|c|}
\hline \hline$i$ & $p$ & $c$ & $h_{i}$ & $r_{i j}$ & $D_{i}$ \\
\hline \hline Retailer 1 & 40 & 7 & 41 & $0.8888,0.8876,0.8790,0.8769$ & Mean 20, Std. Dev. 2 \\
\hline Retailer 2 & 40 & 7 & 42 & $0.9200,0.9192,0.9230,0.9321$ & Mean 30, Std. Dev. 3 \\
\hline Retailer 3 & 40 & 7 & 41 & $0.8767,0.8976,0.8793,0.8921$ & Mean 40, Std. Dev. 5 \\
\hline Retailer 4 & 40 & 7 & 43 & $0.9000,0.9200,0.9300,0.9234$ & Mean 50, Std. Dev. 6 \\
\hline \hline
\end{tabular}

Table 4: Parameter Values for Retailers

Proposition 3. The outcomes of the retailer-supplier matching are stable under the contract size determination rules used in the matching.

Proof. For both retailer-first and supplier-first matching, we can uniquely determine the order of preferences for each retailer and supplier. Therefore the stability of the outcomes of matching is ensured, since the retailer-supplier matching is a simple application of the DA algorithm (Gale and Shapley, 1962).

The stability of the retailer-supplier matching is an important issue. If a matching is unstable, there are some retailers and suppliers who want to change their business partners, and such changes will lead to sequential changes of business partners to other retailers and suppliers, until the matching becomes stable.

Proposition 4. In the Retailer-First (Supplier-First) matching, the result is optimal to retailers (suppliers) under the contract size determination rules used in the matching.

Proof. Proposition 4 is also an obvious application of the results for the Deferred Acceptance Algorithm. See Gale and Shapley (1962) and Roth (2008).

The Proposition 3 and Proposition 4 propose a crucial property for our matching theory application: the matching results are always consistent and fixed unless the parameters constituting equations (1) and (4) are changed.

Given Proposition 3 and Proposition 4, we propose the following matching mechanism. Since meeting the ordering quantity of retailers is more important in many cases and the contract size is usually determined by retailers, we use the contract size $z_{i j}=O_{i j}^{*}$. However, since such $z_{i j}$ are suboptimal for suppliers, we suggest the supplier-first matching.

\section{$6 \quad$ Numerical Illustrations}

In this section, we provide a numerical example using the supplier-first matching with contract size $z_{i j}=O_{i j}^{*}$. The parameter values used in the examples are present in Tables 4 and 5. We consider four retailers and four suppliers, and assume the demand follows Normal distributions. As explaining the numerical example with Suppler First Algorithm with $z_{i j}=$ $O_{i j}^{*}$, we try to have a better understanding on our applied matching theory. These steps and tables turn out the process of the algorithm suggested in Section 4. 


\begin{tabular}{|c||c|c|c|}
\hline \hline$j$ & $c$ & $m_{j}$ & $r_{j i}$ \\
\hline \hline Supplier 1 & 7 & 6.51 & $0.8888,0.9200,0.8767,0.9000$ \\
\hline Supplier 2 & 7 & 6.66 & $0.8876,0.9192,0.8976,0.9200$ \\
\hline Supplier 3 & 7 & 6.72 & $0.8790,0.9230,0.8793,0.9300$ \\
\hline Supplier 4 & 7 & 6.50 & $0.8769,0.9321,0.8921,0.9234$ \\
\hline \hline
\end{tabular}

Table 5: Parameter Values for Suppliers

\begin{tabular}{|l||c|c|c|c|}
\hline \hline & Supplier 1 & Supplier 2 & Supplier 3 & Supplier 4 \\
\hline \hline Retailer 1 & 24.3604 & 24.3596 & 24.3535 & 24.3520 \\
\hline Retailer 2 & 39.2249 & 39.2160 & 39.2590 & 39.3706 \\
\hline Retailer 3 & 50.8796 & 50.9167 & 50.8842 & 50.9069 \\
\hline Retailer 4 & 68.0705 & 68.4732 & 68.7106 & 68.5507 \\
\hline \hline
\end{tabular}

Table 6: Optimal Ordering Quantity of Retailers to Suppliers

Step 0. Each retailer $i$ determines the optimal ordering quantities (Table 6 ), $z_{i j}=O_{i j}^{*}$, for all suppliers $j=1,2,3,4$.

Step 1. As putting $O_{i j}^{*}$ into suppliers' expected profit functions, the suppliers make a preference list over retailers, and offer the first preferable quantity to retailers. In this example, Suppliers 2 and 3 offer to Retailer 3, and Supplier 1 and 4 to Retailer 4.

Step 2. The retailers having the offers determine to accept it or reject it. In this example, Retailer 3 accepts Supplier 2, and Retailer 4 accepts Supplier 4, rejecting others.

Step 3. The rejected Suppliers, in this example Supplier 1 and 3, re-apply to their secondchoice retailers: Supplier 1 applying for Retailer 3 and Supplier 3 applying for Retailer 1. Retailer 3 again selects Supplier 2, rejecting Supplier 1, and Retailer 1 should choose Supplier 3 without any other choice.

Step 4. The matching has been repeated until there remains no more supplier. Then, all suppliers have their matched retailers, and all stable matching pairs exit: (Retailer 1, Supplier 3), (Retailer 2, Supplier 1), (Retailer 3, Supplier 2), (Retailer 4, Supplier 4).

\begin{tabular}{|l||c|c|c|c|}
\hline \hline & First & Second & Third & Fourth \\
\hline \hline Supplier 1 & Retailer 4 & Retailer 3 & Retailer 2 & Retailer 1 \\
\hline Supplier 2 & Retailer 3 & Retailer 4 & Retailer 2 & Retailer 1 \\
\hline Supplier 3 & Retailer 3 & Retailer 1 & Retailer 2 & Retailer 4 \\
\hline Supplier 4 & Retailer 4 & Retailer 3 & Retailer 2 & Retailer 1 \\
\hline \hline
\end{tabular}

Table 7: Preferences of Suppliers 


\begin{tabular}{|c||c|c|c|c|}
\hline \hline & First & Second & Third & Fourth \\
\hline \hline Retailer 1 & Supplier 1 & Supplier 2 & Supplier 3 & Supplier 4 \\
\hline Retailer 2 & Supplier 4 & Supplier 3 & Supplier 1 & Supplier 2 \\
\hline Retailer 3 & Supplier 2 & Supplier 4 & Supplier 3 & Supplier 1 \\
\hline Retailer 4 & Supplier 3 & Supplier 4 & Supplier 2 & Supplier 1 \\
\hline \hline
\end{tabular}

Table 8: Preferences of Retailers

\begin{tabular}{|l||c|c|c|c|}
\hline \hline & Retailer 1 & Retailer 2 & Retailer 3 & Retailer 4 \\
\hline \hline Round 1 & - & - & Supplier 2, 3 & Supplier 1, 4 \\
\hline Round 2 & Supplier 3 & - & Supplier 2, 1 & Supplier 4 \\
\hline Round 3 & Supplier 3 & Supplier 1 & Supplier 2 & Supplier 4 \\
\hline \hline
\end{tabular}

Table 9: Supplier-First Matching

The preference orders of suppliers and retailers are provided in Tables 7 and 8 . The matching procedure and its outcome is shown in Table 9.

We compare the outcome of the supplier-first matching with all other possible matching cases. As we have 4 retailers and 4 suppliers, there are 256 possible matching instances. In Table 10, we observe that the outcome of the supplier-first matching ranks 69 th among all possible cases in terms of the total supplier profit, In Table 11, it ranks 67 th in terms of the total retailer profit. We note that we can avoid the worst matching case (Rank 256) using the supplier-first matching. However, Rank 1 in Table 10 and Rank 1 in Table 11 are not the same matching instance.

All four possible matching scenarios proposed in this paper (supplier-first vs. retailerfirst; retailer's optimal order quantity vs. supplier's optimal shipping quantity) are compared in Table 12. We observe that the resulting profits of retailers and suppliers depend on the two control factors: who proposes first and what contract size is used. While we used in this paper the supplier-first matching algorithm with the contract size as the retailers' optimal order quantities, further study is necessary to determine the two contract factors.

\begin{tabular}{|c||c|c|c|c|c|}
\hline \hline Profit Rank & Supplier 1 & Supplier 2 & Supplier 3 & Supplier 4 & Total Supplier Profit \\
\hline Rank 1 & 17.0891 & 7.49 & 4.6543 & 17.1441 & 46.3775 \\
\hline Rank 2 & 17.0891 & 6.284 & 4.6543 & 17.1441 & 45.1715 \\
\hline$\vdots$ & $\vdots$ & $\vdots$ & $\vdots$ & $\vdots$ & $\vdots$ \\
\hline Rank 69 & $\mathbf{1 0 . 7 3 2 5}$ & $\mathbf{7 . 4 9}$ & $\mathbf{2 . 9 8 3 2}$ & $\mathbf{1 7 . 1 4 4 1}$ & $\mathbf{3 8 . 3 4 9 8}$ \\
\hline$\vdots$ & $\vdots$ & $\vdots$ & $\vdots$ & $\vdots$ & $\vdots$ \\
\hline Rank 256 & 8.052 & 4.4036 & 1.8368 & 8.3506 & 22.643 \\
\hline \hline
\end{tabular}

Table 10: Suppliers' Profit Compared with All Other Possible Matching Instances 


\begin{tabular}{|c||c|c|c|c|c|}
\hline \hline Profit Rank & Retailer 1 & Retailer 2 & Retailer 3 & Retailer 4 & Total Retailer Profit \\
\hline Rank 1 & 658.2259 & 1015.9 & 1313.3 & 1692.6 & 4680.0259 \\
\hline Rank 2 & 658.1822 & 1015.9 & 1313.3 & 1692.6 & 4679.9822 \\
\hline$\vdots$ & $\vdots$ & $\vdots$ & $\vdots$ & $\vdots$ & $\vdots$ \\
\hline Rank 67 & $\mathbf{6 5 7 . 8 6 9 3}$ & $\mathbf{1 0 1 5 . 2}$ & $\mathbf{1 3 1 3 . 3}$ & $\mathbf{1 6 9 1 . 9}$ & $\mathbf{4 6 7 8 . 2 6 9 3}$ \\
\hline$\vdots$ & $\vdots$ & $\vdots$ & $\vdots$ & $\vdots$ & $\vdots$ \\
\hline Rank 256 & 657.7929 & 1015.1 & 1311.7 & 1689.5 & 4674.0929 \\
\hline \hline
\end{tabular}

Table 11: Retailers' Profit Compared with All Other Possible Matching Instances

\begin{tabular}{|c|c|c|c|c|c|}
\hline \hline & $z_{i j}$ & Pair 1 & Pair 2 & Pair 3 & Pair 4 \\
\hline \hline Supplier-First & $O_{i j}^{*}$ & $(\mathrm{R} 1, \mathrm{~S} 3)$ & $(\mathrm{R} 2, \mathrm{~S} 1)$ & $(\mathrm{R} 3, \mathrm{~S} 2)$ & $(\mathrm{R} 4, \mathrm{~S} 4)$ \\
\hline Profits & & $(657.8,2.9)$ & $(1015.2,10.7)$ & $(1313.3,7.4)$ & $(1691.9,17.1)$ \\
\hline \hline Supplier-First & $S_{i j}^{*}$ & $(\mathrm{R} 1, \mathrm{~S} 4)$ & $(\mathrm{R} 2, \mathrm{~S} 3)$ & $(\mathrm{R} 3, \mathrm{~S} 2)$ & $(\mathrm{R} 4, \mathrm{~S} 1)$ \\
\hline Profits & & $(305,9.3)$ & $(152.8,7.4)$ & $(302,11.8)$ & $(701.1,22.3)$ \\
\hline \hline Retailer-First & $O_{i j}^{*}$ & $(\mathrm{R} 1, \mathrm{~S} 1)$ & $(\mathrm{R} 2, \mathrm{~S} 4)$ & $(\mathrm{R} 3, \mathrm{~S} 2)$ & $(\mathrm{R} 4, \mathrm{~S} 3)$ \\
\hline Profits & & $(658.2,8)$ & $(1015.9,10.9)$ & $(1313.3,7.4)$ & $(1692.6,1.8)$ \\
\hline \hline Retailer-First & $S_{i j}^{*}$ & $(\mathrm{R} 1, \mathrm{~S} 3)$ & $(\mathrm{R} 2, \mathrm{~S} 2)$ & $(\mathrm{R} 3, \mathrm{~S} 4)$ & $(\mathrm{R} 4, \mathrm{~S} 1)$ \\
\hline Profits & & $(111.8,4.9)$ & $(226.9,9.1)$ & $(580.9,18.2)$ & $(701.1,22.3)$ \\
\hline \hline
\end{tabular}

Table 12: Four Cases with Two Control Factors

\section{Concluding Remark}

In this paper, we placed emphasis on retailer-supplier coordination with a typical matching algorithm. To develop frameworks for the matching, we used newsvendor models which measure numerical preferences of retailers and suppliers. In our applied matching model, the results of the matching algorithm in retailer-supplier cases depend on contract sizes and who first proposes, satisfying stableness and optimality conditions. These are consistent with the general matching theory.

While this paper takes an important initial step to develop and analyze of the matching models for retailer-supplier coordination system, further research must be conducted to resolve practical problems. For example we assumed identical numbers of retailers and suppliers, but we observe unequal numbers of retailers and supplier in reality. In addition, the strict preference assumption that every matching participant has to evaluate their matching partner differently should be overcome, because it is possible for the game players to have exact identical evaluation between their matching partners.

Another important issue to be addressed in future research is how to determine the contract size as it affects the profit of retailers and suppliers. One possible choice is to choose a fair contract size to both parties, which may be modeled by Nash bargaining games. 
In addition, in this paper, the production capacity of suppliers is not considered. When a retailer's order quantity is greater than a supplier's production capacity, the supplier cannot make a contract with the retailer. A consideration of the production capacity will bring a new dimension to the matching of retailers and suppliers.

\section{References}

Abdulkadiroglu, A. and T. Sonmez (2003). School choice: A mechanism design approach. The American Economic Review 93(3), 729-747.

Cachon, G. (1999). Competitive supply chain inventory management. In S. Tayur, R. Ganeshan, and M. Magazine (Eds.), Quantitative Models for Supply Chain Management, pp. 111-146. Springer Netherlands.

De Boer, L., E. Labro, and P. Morlacchi (2001). A review of methods supporting supplier selection. European Journal of Purchasing E Supply Management 7(2), 75-89.

Deng, S. and W. Elmaghraby (2005). Supplier selection via tournaments. Production and Operations Management 14(2), 252-267.

Elmaghraby, W. (2000). Supply contract competition and sourcing policies. Manufacturing E3 Service Operations Management 2(4), 350.

Gale, D. and L. Shapley (1962). College admissions and the stability of marriage. The American Mathematical Monthly 69(1), 9-15.

Roth, A. (1982). The economics of matching: Stability and incentives. Mathematics of Operations Research, 617-628.

Roth, A. (2008). Deferred acceptance algorithms: History, theory, practice, and open questions. International Journal of Game Theory 36(3), 537-569.

Sobel, M. and D. Turcic (2008). Risk Aversion and Supply Chain Contract Negotiation. Technical report, Working paper, Department of Operations, Weatherhead School of Management, Case Western Reserve University.

Zhang, D. (2008). Essays on supply contracts and dynamic pricing. Ph. D. thesis, University of Iowa. 